\title{
Design Optimization of Pillar Bump Structure for Minimizing the Stress in Brittle Low K Dielectric Material Layer
}

\author{
Xin-Jiang Long ${ }^{1} \cdot$ Jin-Tang Shang ${ }^{1} \cdot$ Li Zhang $^{2}$
}

Received: 27 May 2019 / Revised: 28 June 2019 / Published online: 10 October 2019

(c) The Chinese Society for Metals (CSM) and Springer-Verlag GmbH Germany, part of Springer Nature 2019

\begin{abstract}
$\mathrm{Cu}$ pillar bump offers a number of advantages for flip chip packaging, compared to the conventional solder bump. However, due to its rigidity structure, $\mathrm{Cu}$ pillar bump introduces a lot of stress to the chip, which causes the failure of packaging structures, especially for the advanced node devices which typically have brittle low $\mathrm{K}$ dielectric material. In this paper, for the first time we propose two types of $\mathrm{Cu}$ pillar structures to reduce the stress. The first $\mathrm{Cu}$ pillar structure has bigger $\mathrm{Cu}$ dimensions at the base. The other one is designed to add an additional $\mathrm{Cu}$ pad under the $\mathrm{Cu}$ pillar bump. Finite element analysis is used to study the stress of the both structures, and it is found that with the increase in pillar bump contact area over the chip surface, the stress decreases in both structures. Results also indicate that the $\mathrm{Cu}$ pillar bump undercut induces higher stress, and thin $\mathrm{Cu}_{6} \mathrm{Sn}_{5}$ intermetallic compound has less impact on the stress during flip chip mount reflow. The study provides a novel way to improve the reliability by reducing the stress in the $\mathrm{Cu}$ pillar bump related packaging.
\end{abstract}

Keywords Cu pillar bump · Flip chip · Low K stress · Undercut

\section{Introduction}

The flip chip technology can shrink the packaging size, increase the packaging density, shorten the interconnect length and lower the cost, so this packaging is increasing replace the traditional wire bonding technology. Initially the solder bump was the main selection for interconnect between the chip and substrate, and there are many researches on the performance and reliability of solder bump with different under bump metalization (UBM) structure and solder composition [1-3]. In the recent decade, the $\mathrm{Cu}$ pillar bump is gaining more market share in the high end packaging [4, 5]. The $\mathrm{Cu}$ pillar bump consists of thick plated copper post and solder cap, the solder volume in the solder cap is much smaller than the solder bump. Due to this structure, the $\mathrm{Cu}$ pillar bump can get finer pitch and better electromigration

Available online at http://link.springer.com/journal/40195

Xin-Jiang Long

asen_long@jcap.com.cn

1 Key Laboratory of MEMS of Ministry of Education, Southeast University, Sipailou 2\#, Nanjing 210096, China

2 Jiangyin Changdian Advanced Packaging Co., Ltd., No.275 Binjiang Rd, Jiangyin 214400, China performance, and being compatible with the bump-on-trace (BOT) process which is for low cost and small form-factor application [6-9]. The $\mathrm{Cu}$ pillar bump has much better performance, but it induces higher stress in the chip side, as the $\mathrm{Cu}$ has much higher modulus which add the constraint for the displacement caused by coefficient of thermal expansion (CTE) mismatch between the Si chip and organic substrate $[10,11]$. This stress is a risk to induce the Si cratering and passivation crack, which causes the electronic device functional failure or reliability failure. The stress impact on the low $\mathrm{K}$ chip is more serious and fatal, as the porous brittle low $\mathrm{K}$ material has bad adhesion with the metal and is prone to delamination under the stress. Figure 1 is a typical mechanical failure of low $\mathrm{K}$ material caused by stress induced during flip chip reflow process, and it shows the delamination and crack of low $\mathrm{K}$ layer. In order to lower the risk of low $\mathrm{K}$ layer delamination, wafer fab engineers began to reinforce the Back End of Line (BEoL) structure, for example, tune BEoL stack up configuration to improve the low $\mathrm{K}$ adhesion, and introduce via between layers [12-14]. At the packaging side, the studies mainly focus on adjusting the dimension of packaging structure and selecting packaging material for minimizing the stress.

As the stress in various field is not easy to be measured experimentally, finite element analysis (FEA) is becoming a 


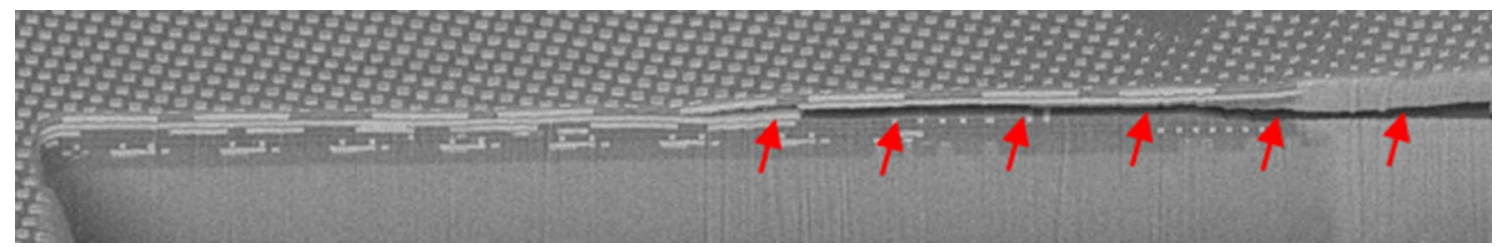

Fig. 1 Failure image of low $\mathrm{K}$ material layer showing delamination and crack beneath $\mathrm{Cu}$ pillars

good alternative method to simulate the stress and guide the structure and process optimization for lower stress, and so does the semiconductor packaging field [15-18]. With this tool, numerous options can be used to optimize the stress of the flip chip package. Zhang et al. [10] used FEA to simulate the stress in low K layer and UBM, and proposed that lower $\mathrm{Cu}$ pillar height, smaller PI opening and higher PI thickness can decrease the stress. Wang et al. [19] adjusted the dimensions of the $\mathrm{Cu}$ pillar bump structure, and reported that the large bump diameter, lower solder thickness and introducing nickel layer can result lower stress. However, the effect of $\mathrm{Cu}$ pillar bump shape on stress distribution is not considered in these studies.

In this study, two kinds of $\mathrm{Cu}$ pillar bump structures and their effect on stress distribution in low $\mathrm{K}$ layer are studied with the FEA. The $\mathrm{Cu}$ post bottom and top size, $\mathrm{Cu} \mathrm{Pad}$ size and thickness are defined as the factors in this study. The undercut caused in bump process and the $\mathrm{Cu}_{6} \mathrm{Sn}_{5} \mathrm{IMC}$ are key factor for the structures and their effect on stress are involved and discussed in this study too.

\section{Cu Pillar Bump Structure Design}

The pillar bump consists of $\mathrm{Cu}$ post and solder cap. The $\mathrm{Cu}$ post is mostly cylindrical shape and the diameter of $\mathrm{Cu}$ post are generally the same at the bottom side (close to the chip) and the top side (close to the solder cap). By varying parameters, totally four groups of $\mathrm{Cu}$ pillar bump structures were designed for investigation as shown in Fig. 2. Tweaking the lithography process, including selecting the different type of photoresists or exposure parameters, the diameter at the bottom and top side of the $\mathrm{Cu}$ post can be changed. For example, the top side diameter is bigger than that of the bottom side, forming a circle truncated cone shape (called as CTC Cu pillar bump) as shown in Fig. 2a. In the group A of the whole design of experiment (DOE), the diameters of the $\mathrm{Cu}$ post at the both top and bottom are changed to study the stress variations.

With two times lithograph and two times plating, one $\mathrm{Cu}$ pad can be added under the bottom side of the Cu pillar, as shown in Fig. 2b, which is called as $\mathrm{Cu}$ pad pillar bump. In the group $\mathrm{B}$, the $\mathrm{Cu}$ post diameters at the bottom and top side are fixed with the same dimensions, while the thickness and diameter of the $\mathrm{Cu}$ pad will be varied.

In $\mathrm{Cu}$ pillar bump process, the sputtered metal layers, such as $\mathrm{Cu}$ seed layer and $\mathrm{Ti}$ barrier layer will be removed with the chemical etchant. This process is known as sputtered layer etching. After etching the sputtered metal layer out of the bump area, part of $\mathrm{t}$ sputtered metal under the bump edge is etched out too, which is known as lateral etching and over etching. The etched metal under the bump is termed as undercut, as illustrated in Fig. 2c. The undercut around the bump peripheral is not connected to the substrate (PI, or chip), which will increase the structural stress. Undercut size is set as the variable in group $\mathrm{C}$, while fixing the other key factors of the structure.

Since intermetallic compound (IMC) will be formed between $\mathrm{Cu}$ post and $\mathrm{Sn}$ cap after reflow, as shown in Fig. 2d, the existence of $\mathrm{Cu}_{6} \mathrm{Sn}_{5}$ IMC is also included to study the effect on low $\mathrm{K}$ material stress.

Among four groups of $\mathrm{Cu}$ pillar structures totally 17 legs are considered in this study, and the dimensions of the key structure factor for the whole DOE are listed in Table 1. In
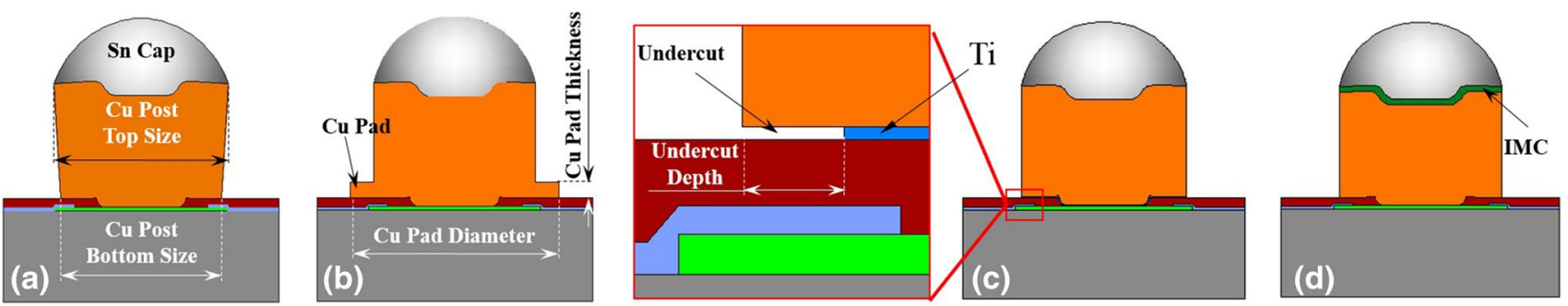

Fig. 2 Two kinds of $\mathrm{Cu}$ pillar bump structures and undercut: a standard $\mathrm{Cu}$ pillar bump, $\mathbf{b} \mathrm{Cu}$ pillar bump with $\mathrm{Cu}$ pad, $\mathbf{c}$ undercut of bump, $\mathbf{d}$ Cu pillar bump with IMC 
Table $1 \mathrm{Cu}$ pillar bump key dimension (Unit: $\mu \mathrm{m}$ )

\begin{tabular}{lllllllll}
\hline No. & Cu pad size & $\mathrm{Cu}$ pad thick. & $\begin{array}{l}\text { Cu post } \\
\text { bot. size }\end{array}$ & $\begin{array}{l}\mathrm{Cu} \text { post } \\
\text { top size }\end{array}$ & $\mathrm{Cu}$ post height & Sn height & $\begin{array}{l}\text { Under- } \\
\text { cut size }\end{array}$ & $\begin{array}{l}\mathrm{Cu}_{6} \mathrm{Sn}_{5} \\
\text { IMC thick- } \\
\text { ness }\end{array}$ \\
\hline $\mathrm{A}-1$ & - & - & 50 & 65 & 35 & 20 & - & - \\
$\mathrm{A}-2$ & - & - & 50 & 50 & 35 & 20 & - & - \\
$\mathrm{A}-3$ & - & - & 50 & 35 & 35 & 20 & - & - \\
$\mathrm{A}-4$ & - & - & 45 & 50 & 35 & 20 & - & - \\
$\mathrm{A}-5$ & - & - & 65 & 50 & 35 & 20 & - & - \\
$\mathrm{B}-1$ & 55 & 3 & 50 & 50 & 32 & 20 & - & - \\
$\mathrm{B}-2$ & 55 & 5 & 50 & 50 & 30 & 20 & - & - \\
$\mathrm{B}-3$ & 60 & 3 & 50 & 50 & 32 & 20 & - & - \\
$\mathrm{B}-4$ & 60 & 5 & 50 & 50 & 30 & 20 & - & - \\
$\mathrm{B}-5$ & 70 & 3 & 50 & 50 & 32 & 20 & - & - \\
$\mathrm{B}-6$ & 70 & 5 & 50 & 50 & 30 & 20 & - & - \\
$\mathrm{C}-1$ & - & - & 50 & 50 & 35 & 20 & 1 & - \\
$\mathrm{C}-2$ & - & - & 50 & 50 & 35 & 20 & 3 & - \\
$\mathrm{C}-3$ & - & - & 50 & 50 & 35 & 20 & 5 & - \\
$\mathrm{D}-1$ & - & - & 50 & 50 & 34 & 19 & - & 2 \\
$\mathrm{D}-2$ & - & - & 50 & 50 & 32 & 17 & - & 6 \\
$\mathrm{D}-3$ & - & - & 50 & 50 & 30 & 15 & - & 10 \\
\hline
\end{tabular}

this study, the polyimide dimension is fixed as $30 \mu \mathrm{m}$ opening diameter and $5 \mu \mathrm{m}$ thick.

\section{Modeling}

Figure $3 \mathrm{a}$ is the sketch of the entire package. The chip size is $7 \mathrm{~mm} \times 7 \mathrm{~mm}$, and top passivation opening and $\mathrm{Al}$ pad are round shape with diameter of $80 \mu \mathrm{m}$ and $90 \mu \mathrm{m}$, respectively. The bump layer is shown in Fig. 3b. The bump pitch peripheral the chip is $120 \mu \mathrm{m}$, and bump pitch is $200 \mu \mathrm{m}$ in center area. The substrate size is $12 \mathrm{~mm} \times 12 \mathrm{~mm}$ with thickness of $0.21 \mathrm{~mm}$.

In modeling, the low $\mathrm{K}$ layer structure is defined as fully covering the Si wafer without any pattern, which simplified the modeling and focused on the $\mathrm{Cu}$ pillar bump structure optimization.

A 3D model is built in the ANSYS. Due to its symmetric structure of the package, the modeling is sliced diagonally into $1 / 2$, as highlighted in red rectangular in Fig. 3a. The global and local views of the model are shown in Fig. 3c-e. The meshes of the modeling in side views and the layer identification are shown in Fig. 3f, g, respectively.

In the actual low $\mathrm{K}$ chip, the structure is complex, due to its high density, thin metal and dielectric layer with different thickness, which causes variable and complex stress in the low $\mathrm{K}$ chip. Any modification or deviation of the metal route will potentially and substantially alternate the stress distribution. As this study main focuses on the effect of bumping structure on the stress within low $\mathrm{K}$ chip, the low $\mathrm{K}$ chip is simplified as being consists of one layer of low $\mathrm{K}$ layer, one layer of $\mathrm{Al}$ pad and one layer of passivation (see Fig. 3g).

In the structure of flip chip packaging, the underfill is necessary to relieve the stress by spreading stress over the entire chip area [20, 21]. But, there is no protection from underfill during the flip chip mount reflow process. So, the stress during flip chip mount reflow is much higher than that after the fully assembly [10, 11]. This added stress poses a high risk to the low $\mathrm{K}$ layer, and will potentially damage the low $\mathrm{K}$ layer causing "White Bump" $[13,22]$. In this paper, the flip chip mount reflow is chosen as the stress loading condition, and the reflow profile is shown as in Fig. 4. Owing to the geometric nonlinearity, the lager deformation function is opened. During flip chip mount reflow process, thermal loading plays a key role in stress of low $\mathrm{K}$ material which are affected by the CTE mismatch between chip and substrate as well as the properties of $\mathrm{Cu}$ pillar bump. The CTE mismatch representative due to thermal loading is given by Eqs. (1) and (2), where $\gamma_{\max }$ is the largest thermal strain due to CTE mismatch, $\Delta$ is thermal expansion differences, $h$ is $\mathrm{Cu}$ pillar bump height, $\alpha_{\text {chip }}$ is CTE of chip, $\alpha_{\text {substrate }}$ is CTE of substrate, $T_{\text {reflow }}$ is temperature of reflow process, $T_{0}$ is reference temperature and $l$ is half of largest acting package diagonal length. The material properties of the models and the layer thickness are listed in Table 2.

$\gamma_{\max }=\Delta / h=(\Delta \alpha)(\Delta T) l / h$,

$\Delta=\left(\alpha_{\text {chip }}-\alpha_{\text {substrate }}\right)\left(T_{\text {reflow }}-T_{0}\right) l=(\Delta \alpha)(\Delta T) l$, 

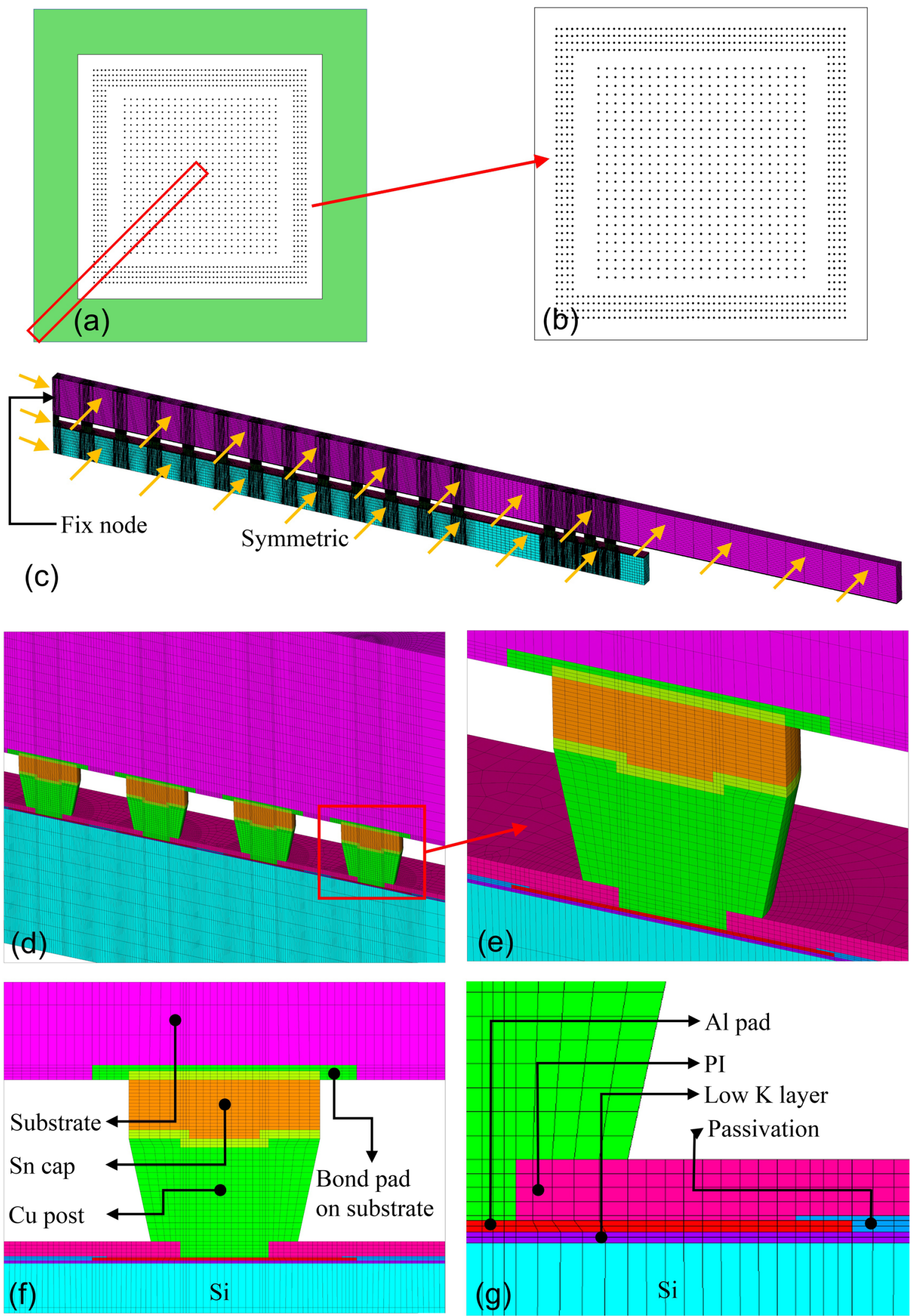

Fig. 3 Illustration of the modeling: a the sketch of entire package, $\mathbf{b}$ bump layout, $\mathbf{c}$ global view of model of $1 / 2$ of one strip in the diagonal of the package, $\mathbf{d}$, $\mathbf{e}$ local model of bump area, $\mathbf{f}$ side view of local model of bump area, $\mathbf{g}$ layer identification 


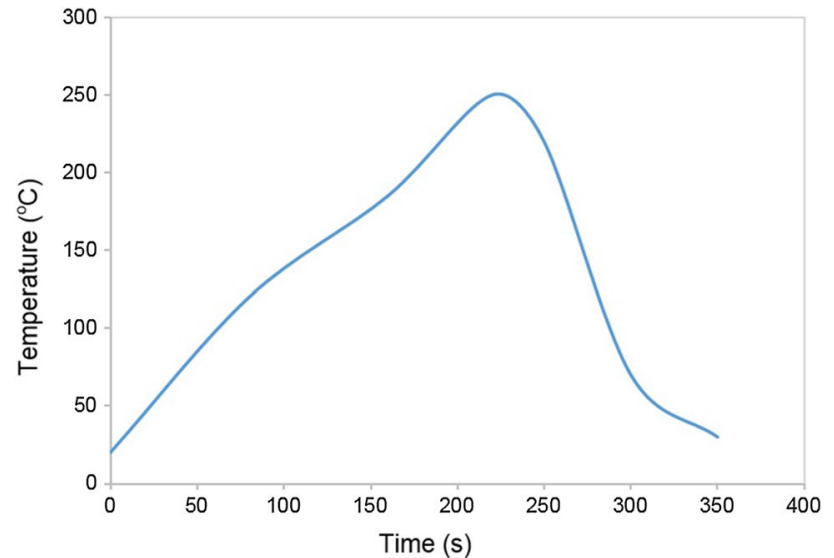

Fig. 4 Reflow profile of the $\mathrm{Cu}$ pillar bump

Since $\mathrm{Sn}$ is viscoelastic in the temperature range of reflow, the ANAND viscoelastic modeling is involved for $\mathrm{Sn}$. ANAND's viscoplasticity for $\mathrm{Sn}$ is described by Eq. (3) and three corresponding evolution equations are given as Eqs. (4), (5) and (6), where $\varepsilon_{\mathrm{p}}$ is inelastic strain rate, $A$ is pre-exponential factor, $\xi$ is multiplier of stress, $\sigma$ is the equivalent stress, $s$ is the internal variable, $Q$ is the activation energy, $k$ is the gas constant, $T$ is current absolute temperature, $h_{0}$ is hardening/ softening constant, $\alpha$ is the strain rate sensitivity of hardening/ softening, $S^{*}$ is the saturation value of internal variable for a given temperature and strain rate, $\hat{S}$ is a coefficient for deformation resistance saturation value and $n$ is the strain rate sensitivity for saturation value. Table 3 lists the material parameters of ANAND model for Sn.

$\frac{\mathrm{d} \varepsilon_{\mathrm{p}}}{\mathrm{d} t}=A \sinh \left(\xi \frac{\sigma}{S}\right)^{\frac{1}{m}} \exp \left(-\frac{Q}{k T}\right)$

$\frac{\mathrm{d} s}{\mathrm{~d} t}=\left[h_{0}(|B|)^{\alpha} \frac{B}{|B|}\right] \frac{\mathrm{d} \varepsilon_{p}}{\mathrm{~d} t}$,
Table 3 Material parameters of ANAND model for $\mathrm{Sn}$

$B=1-\frac{s}{s^{*}}$

$s^{*}=\hat{s}\left[\frac{1}{A} \frac{\mathrm{d} \varepsilon_{\mathrm{p}}}{\mathrm{d} t} \exp \left(-\frac{Q}{k T}\right)^{n}\right]$.

\section{Results and Analysis}

\subsection{FEA Result of Different Pillar Bump Structure}

During reflow, substrate deformation is much higher than that in Si chip, due to the CTE mismatch between these two components. In macro view, $\mathrm{Cu}$ pillar bump acts as a bridge to transfer the displacement between the substrate side to the chip side; as the $\mathrm{Cu}$ is much rigid and not able to relieve the stress by deformation easily, which induces high stress in the low $\mathrm{K}$ layer. In micro aspect, the CTE mismatch at the chip side, including the polyimide, passivation, $\mathrm{Al}$ metal, low $\mathrm{K}$, silicon, also add stresses in the low $\mathrm{K}$ layer.

The low $\mathrm{K}$ material is brittle and weak in tension, and the main structure failure is delamination and crack. Therefore, this study focuses on the stress distribution in the low $\mathrm{K}$
Table 2 Material properties and layer thickness

\begin{tabular}{lllll}
\hline Material & Modulus $(\mathrm{GPa})$ & Poisson ratio & $\mathrm{CTE}\left(\mathrm{ppm} /{ }^{\circ} \mathrm{C}\right)$ & Thickness $(\mu \mathrm{m})$ \\
\hline $\mathrm{Si}$ & 162.7 & 0.28 & 3.5 & 150 \\
Low K & 11.54 & 0.21 & 10.1 & 1 \\
$\mathrm{Al}$ & 74 & 0.33 & 21.5 & 1 \\
Passivation & 210 & 0.27 & 2 & 1.45 \\
Polyimide & 3.5 & 0.34 & 35 & 5 \\
$\mathrm{Cu}$ & 122 & 0.35 & 17 & Table 1 \\
$\mathrm{Sn}$ & $45.7 @-40$ & 0.32 & 19.1 & Table 1 \\
& $34.3 @ 25$ & & & \\
& $29.9 @ 50$ & & & Table 1 \\
$\mathrm{Cu}_{6} \mathrm{Sn}_{5} \mathrm{IMC}$ & $16.7 @ 125$ & & 16 & 2100 \\
Substrate $^{110}$ & 27 & 0.30 & $X, Y=10$ & \\
& & 0.18 & $Z=23$ & \\
\hline
\end{tabular}


layer, and the in-plane stress and out-plane stress are used to evaluate the stress level caused by the flip chip structure with $\mathrm{Cu}$ pillar bump.

Figure 5 is the stress contour of simulated result of low $\mathrm{K}$ layer stress caused by structure A-2 Cu pillar bump. The maximum stress in low $\mathrm{K}$ layer is closed to the interface between the low $\mathrm{K}$ layer and metal layer. From the stress contour of all simulated structures, the outer most pillar bump shows higher stress than the other pillar bumps and the peak value of the stress is at the outside of the diagonal of the package, which is consistent to the results reported by Gallois-Garreignot et al. [23]. In each $\mathrm{Cu}$ pillar structure, the maximum stress is at the polyimide opening area with the highest stress gradient, which is same with the studies of Zhang from UTAC [10] and Lee et al. from Amkor [11]. Lianto et al. [24] studied the UBM-Al interface stress in $\mathrm{Cu}$ pillar flip chip packaging, and found the maximum stress is located at the PI opening area and $\mathrm{Al}$ pad edge area too. The maximum tensile and compressive stress of the in-plane stress and out-plane stress in the low $\mathrm{K}$ layer are listed in Table 4.

\subsection{Effect of Cu Post Top and Bottom Size}

The in-plane stress plots of structure group A along the interface in the diagonal direction of package are shown in Fig. 6a, and the stress plot path is indicated in Fig. 5b. There are four peaks in the in-plane stress under the outer most $\mathrm{Cu}$ pillar bump in each structure. Peaks 1 and 2 are at the polyimide opening area as described above, and its location is not changed as the polyimide size are fixed in this study. Peak 1 is the in-plane tensile stress and the peak 2 is the in-plane compressive stress. Peaks 3 and 4 are related with the top passivation layer and $\mathrm{Al}$ pad, respectively, in which the top passivation opening and $\mathrm{Al}$ pad are both round shaped with diameter of $80 \mu \mathrm{m}$ and $90 \mu \mathrm{m}$, respectively. There is no stress peak at the edge area of the $\mathrm{Cu}$ pillar bump, which indicates that the polyimide can
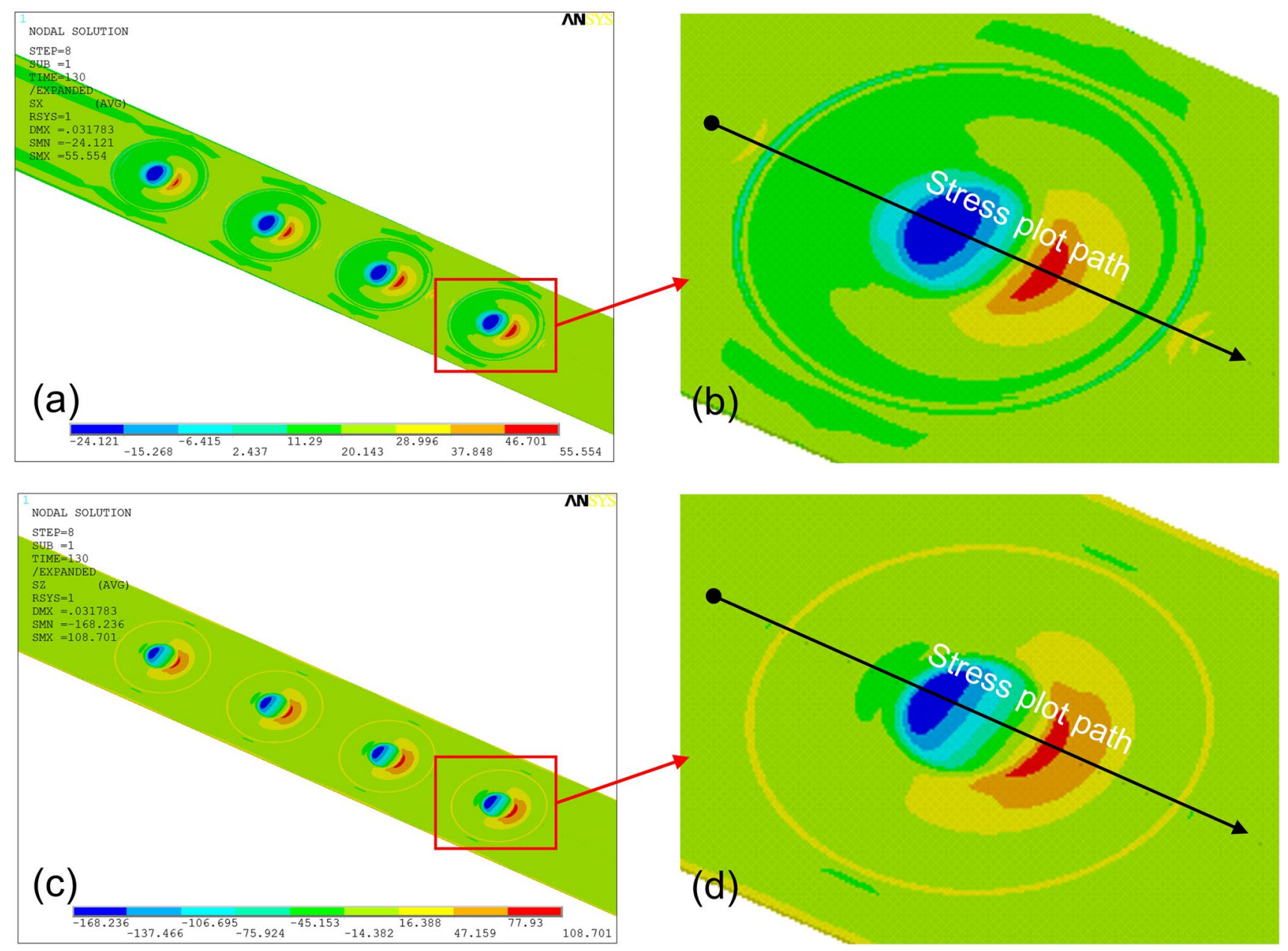

Fig. 5 Simulated stress distribution: a stress contour of in plane, $\mathbf{b}$ zoom in for stress contour of in plane, $\mathbf{c}$ stress contour of out plane, $\mathbf{d}$ zoom in for stress contour of out plane 
Table 4 Maximum stress in low $\mathrm{K}$ layer and out of low K layer versus $\mathrm{Cu}$ pillar bump structure

\begin{tabular}{lllll}
\hline No. & $\begin{array}{l}\text { Tensile stress-in } \\
\text { plane (MPa) }\end{array}$ & $\begin{array}{l}\text { Compressive stress-in } \\
\text { plane (MPa) }\end{array}$ & $\begin{array}{l}\text { Tensile stress-out } \\
\text { plane (MPa) }\end{array}$ & $\begin{array}{l}\text { Compressive } \\
\text { stress-out plane } \\
\text { (MPa) }\end{array}$ \\
\hline A-1 & 64.969 & -29.14 & 139.181 & -190.524 \\
A-2 & 55.554 & -24.121 & 108.701 & -168.236 \\
A-3 & 43.237 & -19.418 & 63.067 & -131.37 \\
A-4 & 65.506 & -26.703 & 153.145 & -184.957 \\
A-5 & 35.959 & -24.644 & 47.067 & -138.103 \\
B-1 & 46.163 & -23.188 & 64.121 & -143.992 \\
B-2 & 45.987 & -23.205 & 63.008 & -143.092 \\
B-3 & 42.677 & -23.669 & 56.839 & -141.131 \\
B-4 & 41.319 & -23.933 & 51.478 & -138.084 \\
B-5 & 37.868 & -23.801 & 49.517 & -139.623 \\
B-6 & 36.918 & -24.799 & 45.361 & -134.993 \\
C-1 & 62.495 & -25.088 & 130.707 & -174.911 \\
C-2 & 70.63 & -27.632 & 166.996 & -189.98 \\
C-3 & 74.819 & -30.524 & 205.085 & -206.632 \\
D-1 & 55.535 & -23.279 & 109.266 & -161.234 \\
D-2 & 55.385 & -25.213 & 106.152 & -170.369 \\
D-3 & 54.415 & -26.231 & 102.291 & -173.706 \\
\hline
\end{tabular}
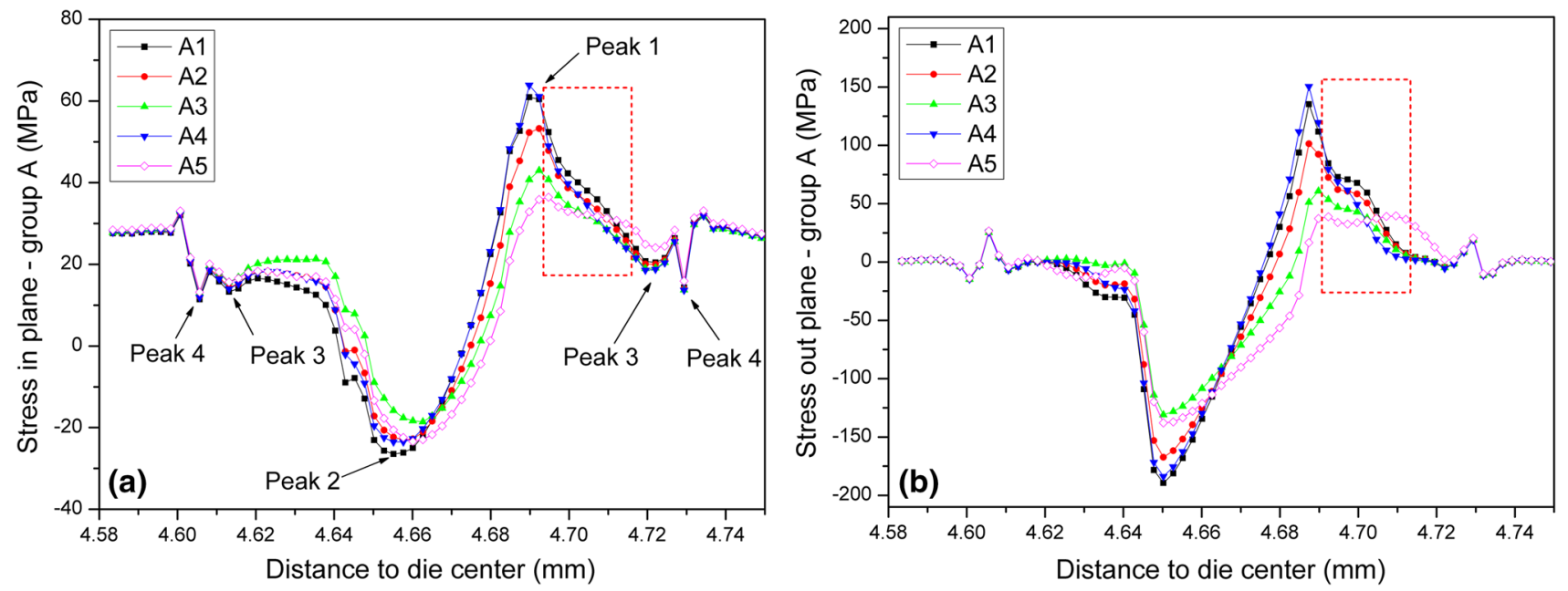

Fig. 6 Interfacial stresses of group A structure: a in-plane stress, $\mathbf{b}$ out-plane stress

work as the buffer to relieve the stress. This is also verified by the works of Cheng et al. [25] as well as Wang et al. [26]. In the area far away from the $\mathrm{Cu}$ pillar bump, the inplane stress is approximately $\sim 27 \mathrm{MPa}$, which is caused by the different mechanical properties between silicon, low $\mathrm{K}$ material, passivation and $\mathrm{Al}$ pad, and this stress is not related to the $\mathrm{Cu}$ pillar bump structure. The out-plane stress distribution is shown in Fig. 6b. The out-plane stress in the area further away from the $\mathrm{Cu}$ pillar bump is close to zero, as the out-plane stress is mainly caused by the $\mathrm{Cu}$ pillar bump.
The stress plot of the area where the $\mathrm{Cu}$ pillar bump overlaps the polyimide is highlighted with the red frame in Fig. 6a, b. The stress gradient of this area in structure A-1 is much higher than that in structure A-3. The A-1 and A-3 $\mathrm{Cu}$ pillar bumps have the same bottom size of $50 \mu \mathrm{m}$ in diameter, while the top size of $\mathrm{Cu}$ post in A-3 is only $35 \mu \mathrm{m}$ which is $30 \mu \mathrm{m}$ smaller than that in A-1 (top size is $65 \mu \mathrm{m}$, see Table 1). Structure A-3 can be regarded as firstly shrinking both the bottom and top size of structure A-2 (initially $50 \mu \mathrm{m}$ ) to $35 \mu \mathrm{m}$ to lower the stiffness of the $\mathrm{Cu}$ pillar bump and make bump easier to deform under the 
effect of the stress, which can decreases constraint of the relative displacement between chip and substrate to lower the stress on the chip side. Then, increase the shrunk bottom diameter to the initial $50 \mu \mathrm{m}$, which enlarges the contact area between bump and chip, and can share stress loading at the polyimide surface. Vice versa, this analysis is suitable for demonstrating why structure A-1 has higher stress in low $\mathrm{K}$ layer. As the result, A-3 induces 43.24 MPa in-plane tensile stress (about $66 \%$ of that in structure A-1) and $63.07 \mathrm{MPa}$ out-plane tensile stress (about $45 \%$ of that in structure A-1).

From the stress plot of structure A-5 in Fig. 6, one can see that the low $\mathrm{K}$ layer tensile stress concentration area underneath polyimide is larger than that in other structure, while the stress in peak 1 area is lower than others significantly. This can be understood that structure A-5 has larger bottom size and connect area in polyimide, which shares more loading and lowers the stress in peak 1 area. As a result, in structure A-5, the tensile stress in peak 1 area is as low as the whole overlapping area between the $\mathrm{Cu}$ pillar and polyimide. Although structure A-4 has the same top size with structure A-5, structure A- 4 has $82 \%$ higher in plane tensile stress and $225 \%$ higher out plane tensile stress than those of structure A-5, because the bottom size of structure A-4 is smaller than that of structure A-5.

According to the result from the group A structure, we can conclude that increasing the bottom size and (or) decreasing the top size of the Cu post can lower the stress in low $\mathrm{K}$ layer of the chip side.

\subsection{Effects of Cu Pad Size and Thickness}

The stress plots along the interfaces of the structure B and A-2 are shown in Fig. 7.

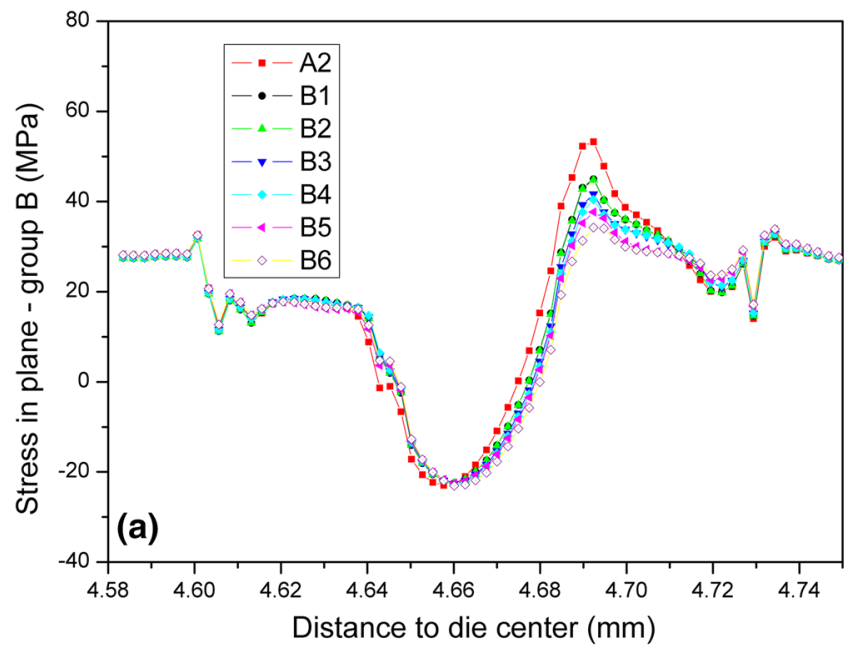

Compared with structure A-2 whose top size and bottom size are $50 \mu \mathrm{m}$, the difference in structure $\mathrm{B}$ is that $\mathrm{Cu}$ pad is added under the bottom of $\mathrm{Cu}$ post. According to the simulation results, the structure B can lower 16-33\% in-plane tensile stress, $41-58 \%$ out-plane tensile stress, and 14-19\% out-plane compressive stress, compared with those in structure A-2. These results do match with that in structure A. $\mathrm{By}$ increasing the $\mathrm{Cu}$ pad diameter, the out-plane tensile and compressive stresses are decreased, so does the in-plane tensile stress. The $\mathrm{Cu}$ pad increases the bottom size of the $\mathrm{Cu}$ post and increases the contact area between the $\mathrm{Cu}$ post and polyimide, which is to spread the stress to more area on soft polyimide surface. These results verify the simulation results in structure A. However, the structure B does not change the in-plane compressive stress, compared with that in structure A-2, because the structure B has no effect on in-plane relative displacement between the bump bottom and chip, and does not induce additional component of the compressive stress in plane.

Adding thick $\mathrm{Cu}$ pad at the bottom of $\mathrm{Cu}$ post has the positive effect to lower the stress, because the thicker $\mathrm{Cu}$ pad is stiffer and can decrease its deformation at the maximum stress area, and more stress are loading at the polyimide layer.

These results are applied to optimize actual packaging design for solving the problem of mechanical failure in chip active area under $\mathrm{Cu}$ pillar bump. Although this chip is not built with the low $\mathrm{K}$ material, the experiment result matches with the result aforementioned. The $\mathrm{Cu}$ pad dimension, $\mathrm{Cu}$ post height and PI thickness are adjusted in this experiment, and these key dimensions of pillar bump are listed in Table 5. The chip size is $0.9 \mathrm{~mm} \times 1.4 \mathrm{~mm}$, and PI opening is fixed as $70 \mu \mathrm{m} .120$ pieces of chips with each kind of $\mathrm{Cu}$ pillar bumps, totally 480 pieces of

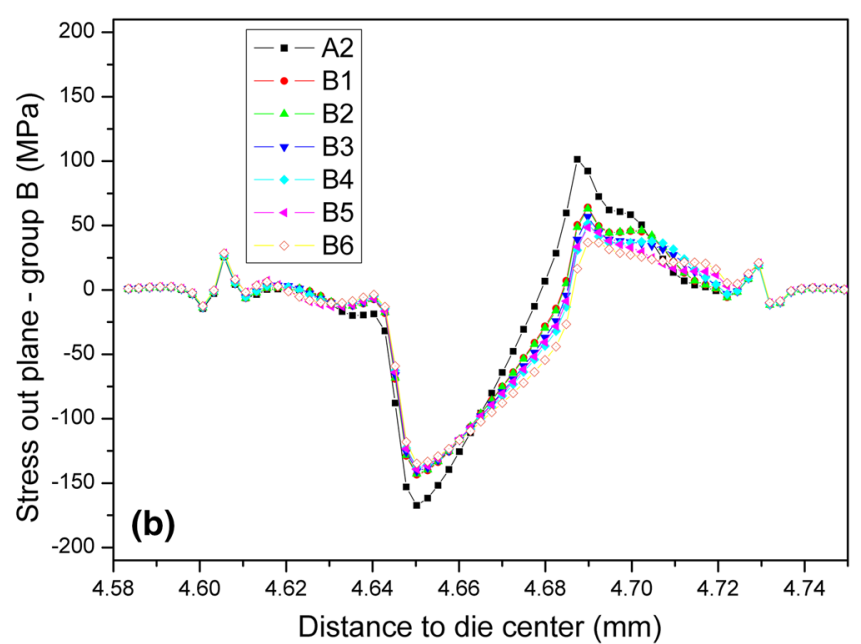

Fig. 7 Interfacial stresses of group B structure compared to A-2 structure: a in-plane stress, b out-plane stress 
Table $5 \mathrm{Cu}$ pillar bump key dimension for design optimization application and experiment result (Unit: $\mu \mathrm{m})$

\begin{tabular}{llllllll}
\hline No. & Cu pad size & Cu pad thick. & Cu post size & Cu post height & Sn height & PI thick. & Failure rate \\
\hline L-1 & - & - & 120 & 65 & 27 & 10 & $10 / 120^{\text {a }}$ \\
L-2 & 160 & 10 & 120 & 55 & 27 & 10 & $0 / 120$ \\
L-3 & 160 & 10 & 120 & 55 & 27 & 5 & $2 / 120$ \\
L-4 & 200 & 10 & 120 & 55 & 27 & 5 & $0 / 120$ \\
\hline
\end{tabular}

${ }^{\mathrm{a}} 10$ stands for the quantity of failed chips, and 120 stands for the quantity of inspected chips under optical microscope
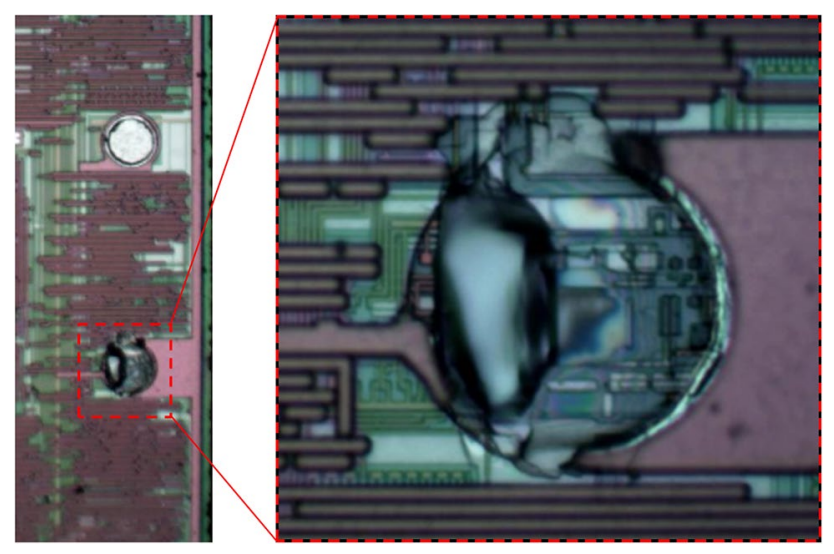

lower the risk of chip mechanical failure, and the PI layer has the positive effect to decrease the failure rate too. The experimental results in Table 5 clearly verify the theoretical design rule on the effect of $\mathrm{Cu}$ pad size and thickness as illustrated in Fig. 7.

\subsection{Effect of Undercut Size}

The stress plots along the interfaces for the structure $\mathrm{C}$ and A-2 are shown in Fig. 9.

The undercut causes disconnect between the $\mathrm{Cu}$ pillar bump edge area and polyimide. Although the bottom size of $\mathrm{Cu}$ pillar bump is not changed, the undercut decreases the $\mathrm{Cu}$ post contact area on the polyimide surface, which induces the higher stress as being similar to the shrinkage of the bottom size of $\mathrm{Cu}$ post. According to the simulation result of structure $C$ as shown in Table 4 , the $5 \mu \mathrm{m}$ undercut will induce $88 \%$ higher out-plane tensile stress. With the underfill, the effect of undercut on the stress is not similar to the shrinkage of the bottom size of $\mathrm{Cu}$ post, as the undercut does not change the $\mathrm{Cu}$ post side profile that contributes to the stress distribution near the bump area mostly.

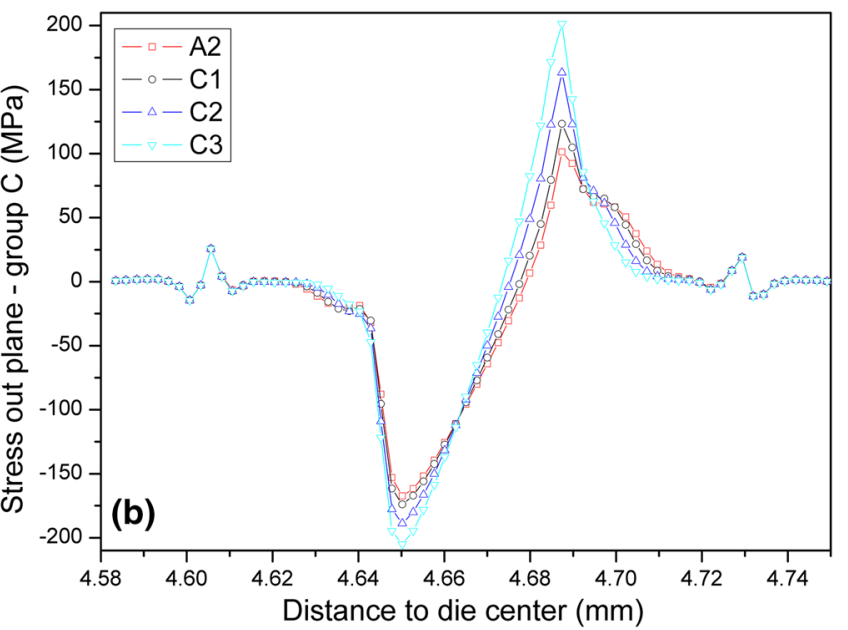

Fig. 9 Interfacial stresses of group C structure compared to A-2 structure: a in-plane stress, b out-plane stress 


\subsection{Effect of $\mathrm{Cu}_{6} \mathrm{Sn}_{5}$ IMC}

In group $\mathrm{D}, \mathrm{Cu}_{6} \mathrm{Sn}_{5}$ IMC is added in the $\mathrm{Cu}$ pillar bump, based on the standard $\mathrm{Cu}$ pillar bump structure A-2. $\mathrm{Cu}_{6} \mathrm{Sn}_{5}$ IMC thickness is defined as $2 \mu \mathrm{m}, 6 \mu \mathrm{m}$ and $10 \mu \mathrm{m}$ in legs D-1, D-2 and D-3, respectively. The Cu post height and Sn height are decreased to $1 \mu \mathrm{m}, 3 \mu \mathrm{m}$ and $5 \mu \mathrm{m}$ in corresponding legs in order to fix the whole bump height at the same value. As shown in Fig. 10, the stress distribution of structure D matches well with that of standard pillar bump structure A-2. The effect of 2-10 $\mu \mathrm{m}$ thick $\mathrm{Cu}_{6} \mathrm{Sn}_{5}$ IMC on low $\mathrm{K}$ material stress is little, being less than $10 \%$ variation based on structure A-2. As the IMC thickness is small compared with the pillar bump height, and its mechanical properties including the CTE, modulus and Poisson rate are similar with that of $\mathrm{Cu}$, and the loading condition is only one cycle of flip chip reflow, the existence of IMC on the stress distribution on low $\mathrm{K}$ material can be neglected. Although in this study IMC has less effect on the stress of low $\mathrm{K}$ material during flip chip mount reflow, its harmful effect on the reliability must be considered during service, because the interface of IMC with $\mathrm{Cu}$ and $\mathrm{Sn}$ is the weak point for fracture generation under fatigue loading in application [3, 27].

\subsection{Parametric Optimization of Structure Factors}

After setting the data of $\mathrm{Cu}$ pillar bump structure in Table 1 as the variants and the stress value in Table 4 as response, the ANOVA analysis was then conducted. In structure A and structure $\mathrm{C}$, there is no $\mathrm{Cu}$ pad under the pillar bump; thus, the $\mathrm{Cu}$ pad size is the same as the bottom diameter of the $\mathrm{Cu}$ pillar bump and the $\mathrm{Cu}$ pad thickness is set as $0 \mu \mathrm{m}$. As the effect of the IMC on stress is less, it is excluded from this analysis. The final ANOVA results are shown in Table 6.

The rank of the structure factors for in-plane tensile stress is Undercut Size $>\mathrm{Cu}$ Post Top Size $>\mathrm{Cu} \mathrm{Pad}$ Size $>\mathrm{Cu}$ Post Bottom Size $>\mathrm{Cu}$ Pad Thickness. For out-plane tensile stress, the rank of the factors is Undercut Size $>\mathrm{Cu}$ Post Top Size $>\mathrm{Cu}$ Pad Thickness $>\mathrm{Cu}$ Post Bottom Size $>\mathrm{Cu}$ Pad Size.

Increasing the $\mathrm{Cu}$ post bottom size, meanwhile decreasing the $\mathrm{Cu}$ post top size can lower the stress in the low $\mathrm{K}$ layer. However, it is not easy to realize with the current existing
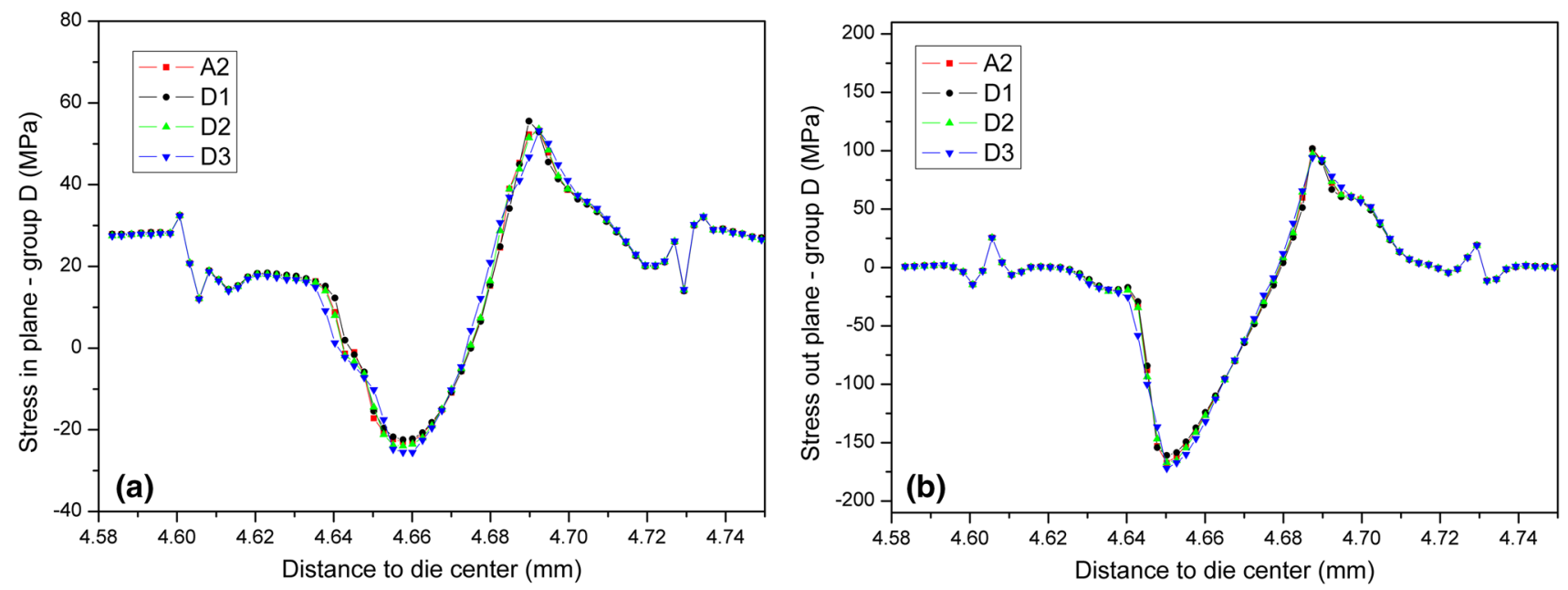

Fig. 10 Interfacial stresses of group D structure compared to A-2 structure: a in-plane stress, b out-plane stress

Table 6 Variance analysis for structure factors

\begin{tabular}{lcccc}
\hline Factor & $\begin{array}{l}\text { Tensile stress-in } \\
\text { plane }\end{array}$ & $\begin{array}{l}\text { Compressive stress- } \\
\text { in plane }\end{array}$ & $\begin{array}{l}\text { Tensile stress-out } \\
\text { plane }\end{array}$ & $\begin{array}{l}\text { Compressive } \\
\text { stress-out } \\
\text { plane } \\
P \text { value }\end{array}$ \\
\hline Undercut size & $P$ value & $P$ value & $P$ value & $<0.0001$ \\
Cu post top size & 0.0001 & 0.0004 & $<0.0001$ & $<0.0001$ \\
Cu pad size & 0.0001 & $<0.0001$ & 0.0014 & 0.0855 \\
Cu post bot. size & 0.0056 & 0.5747 & 0.0514 & 0.0141 \\
Cu pad thickness & 0.0100 & 0.4058 & 0.0138 & 0.0035 \\
\hline
\end{tabular}


technology in the industry. Even making the Cu post bottom size bigger by $5 \mu \mathrm{m}$ than the top size is difficult due to the limitation of lithography and electro-plating process. Adding $\mathrm{Cu}$ pad under the $\mathrm{Cu}$ post is more applicable in the process, and it has the positive effect for relieving the stress within the packaging structure.

\section{Conclusion}

In order to minimize the stress in the low $\mathrm{K}$ layer during flip chip packaging process, four groups of pillar bump structures including the circle truncated cone shape $\mathrm{Cu}$ pillar bump, $\mathrm{Cu}$ pad pillar bump, $\mathrm{Cu}$ pillar bump with undercut and $\mathrm{Cu}$ pillar bump with IMC, were designed to investigate the stress distribution in the low $\mathrm{K}$ layer using FEA method. Including $\mathrm{Cu}$ pillar bottom diameter and top diameter, $\mathrm{Cu}$ pad diameter and thickness, undercut size and IMC thickness totally six factors are adjusted during simulation and discussion. The maximum stress was located near the polyimide opening area, and the polyimide can work as the buffer layer to relieve the stress in the low $\mathrm{K}$ layer under the $\mathrm{Cu}$ pillar bump edge area. The smaller top size of the $\mathrm{Cu}$ post and the bigger bottom size of the $\mathrm{Cu}$ post can lower the stress in the low $\mathrm{K}$ layer. Adding one $\mathrm{Cu}$ pad under the $\mathrm{Cu}$ pillar bump decreases the tensile stress in the low $\mathrm{K}$ layer. The bigger undercut induces more stress in the low $\mathrm{K}$ layer. The thin IMC has less effect on the stress during the flip chip mount reflow, although its effect on long-term service reliability cannot be neglected. Compared to the normal cylindrical shape $\mathrm{Cu}$ pillar bump, both the circle truncated cone shape $\mathrm{Cu}$ pillar bump and $\mathrm{Cu}$ pad pillar bump structures can reduce the stress effectively. However, $\mathrm{Cu}$ pad pillar bump is more applicable in industry due to its easy realization.

Acknowledgements The technical support and discussion from Cheng $\mathrm{Xu}$, Kim-Hwee Tan and Zhi-Quan Liu are acknowledged.

\section{References}

[1] W.J. Choi, E.C.C. Yeh, K.N. Tu, P. Elenius, H. Balkan, Electromigration of flip chip solder bump on $\mathrm{Cu} / \mathrm{Ni}(\mathrm{V}) / \mathrm{Al}$ thin film under bump metallization, in Paper Presented at the 52nd Electronic Components and Technology Conference, San Diego, CA, USA (2002)

[2] Y.H. Tian, C.Q. Wang, W.F. Zhou, Acta Metall. Sin. (Engl. Lett.) 19, $301(2006)$

[3] S. Li, X.W. Hu, W.G. Zhang, Y.L. Li, X.X. Jiang, Acta Metall. Sin. (Engl. Lett.) 32, 629 (2019)

[4] T. Wang, F. Tung, L. Foo, V. Dutta, Studies on a novel flip-chip interconnect structure-pillar bump, in Paper Presented at the 51st Electronic Components and Technology Conference, Orlando, FL, USA (2001)
[5] N.M. Patel, V. Wakharkar, S. Agrahram, N. Deshpande, M. Pang, R. Tanikella, R. Manepalli, P. Stover, J. Jackson, R. Mahajan, P. Tiwari, Int. Technol. J. 12, 145 (2008)

[6] B. Ebersberger, C. Lee, Cu pillar bumps as a lead-free drop-in replacement for solder-bumped, flip-chip interconnects, in Paper Presented at the 58th Electronic Components and Technology Conference, Lake Buena Viata, FL, USA (2008)

[7] D. Gupta, H. Sato, Y. Nakadaira, Cu pillars on substrates-a low cost alternative for the next generation for flip chip packaging technology, in Paper Presented at the 60th Electronic Components and Technology Conference, Las Vegas, NV, USA (2010)

[8] K.M. Chen, C.Y. Wu, H.L. Chou, P.C. Kuo, Cu pillar bump-ontrace (BoT) design for ultra low-k packaging, in Paper Presented at the 8th International Microsystems, Packaging, Assembly and Circuits Technology Conference, Taipei, Taiwan (2013)

[9] B.K. Applet, H. Chung, C. Chen, R. Wang, M. Hung, Low cost fcCSP based on $\mathrm{Cu}$ pillar, in Paper Presented at the 13th Electronics Packaging Technology Conference, Singapore, Singapore (2011)

[10] X.R. Zhang, W.H. Zhu, B.P. Liew, M. Gaurav, A. Yeo, K.C. Chan, Copper pillar bump structure optimization for flip chip packaging with $\mathrm{Cu} /$ low-K stack, in Paper Presented at the 11th International Thermal, Mechanical and Multi-Physics Simulation, and Experiments in Microelectronics and Microsystems, Bordeaux, France (2010)

[11] M.W. Lee, J.Y. Kim, J.D. Kim, C.H. Lee, Below 45 nm low-k layer stress minimization guide for high-performance flip-chip packages with copper pillar bumping, Paper Presented at the 60th Electronic Components and Technology Conference, Las Vegas, NV, USA (2010)

[12] C.J. Zhai, U. Ozkan, A. Dubey, R.C. Blish, R.N. Master, Investigation of $\mathrm{Cu} /$ low-k film delamination in flip chip packages, in Paper Presented at the 56th Electronic Components and Technology Conference, San Diego, CA, USA (2006)

[13] S.W. Lee, B.W. Jang, J.K. Kim, Y.H. Jung, Y.B. Kim, H.G. Song, S.Y. Kang, Y.M. Kang, S.M. Lee, K.C. Park, C.S. Ju, G.R. Kim, A Study on the chip-package-interaction for advanced devices with ultra low-k dielectric, in Paper Presented at the 62nd Electronic Components and Technology Conference, San Diego, CA, USA (2012)

[14] M. Gonzalez, K. Vanstreels, V. Cherman, K. Croes, L. Kljucar, I. D. Wolf, Z. Tőkei, Mechanical stability of Cu/low-k BEOL interconnects, in Paper Presented at the IEEE International Reliability Physics Symposium, Waikoloa, HI, USA (2014)

[15] W.C. Dong, D.B. Gao, S.P. Lu, Acta Metall. Sin. (Engl. Lett.) 32, 618 (2019)

[16] N.Y. Ye, M. Cheng, S.H. Zhang, Acta Metall. Sin. (Engl. Lett.) 28, 1510 (2015)

[17] L. Jiang, L. Zhang, Z. Q. Liu, Acta Metall. Sin. (Engl. Lett.) https ://doi.org/10.1007/s40195-019-00875-6, (2019)

[18] E. Suhir, J. Mater. Sci. Mater. Electronics 29, 2676 (2018)

[19] L. Wang, C. Xu, W. Zhang, Investigation of thermal-mechanical stress and chip-packaging-interaction issues in low-k chips, in Paper Presented at the 16th International Conference on Electronic Packaging Technology, Changsha, Hunan, China (2015)

[20] D.W. Wang, K.I. Papathomas, IEEE Trans. Compon. Hybrids Manuf. Technol. 16, 863 (1993)

[21] Y. He, B.E. Moreira, A. Overson, S.H. Nakamura, Thermochim. Acta 357-358, 1 (2000)

[22] Y. Pan, J.A. Zitz, D.L. Questad, K.K. Sikka, Chip package interaction: an experiment study on white bump mitigation using flat laminates, in Paper Presented at the 64th Electronic Components and Technology Conference, Orlando, FL, USA (2014)

[23] S. Gallois-Garreignot, G. Hu, V. Fiori, M. Sorrieul, C. Moutin, C. Tavernier, Chip package interactions: package effects on copper pillar bump induced BEoL delaminations and associated 
numerical developments, in Paper Presented at the 65th Electronic Components and Technology Conference, San Diego, CA, USA (2015)

[24] P. Lianto, H.Y. Li, R. Balamurugan, J. Wei, N. Binte Jaafar, L.C.E. Wai, A. Sundarrajan, IEEE Trans. Compon. Packag. Manuf. Technol. 6, 1120 (2016)

[25] P.J. Cheng, C.M. Chung, T.M. Pai, D.Y. Chen, A challenge of $45 \mathrm{~nm}$ extreme low-k chip using Cu pillar bump as 1 st interconnection, in Paper Presented at the 60th Electronic Components and Technology Conference, Las, Vegas, NV, USA (2010)
[26] W. Wang, D. Zhang, Y. Sun, D. Rae, L. Zhao, J. Zheng, M. Schwarz, M. Shah, A. Syed, Study of polyimide in chip package interaction for flip-chip $\mathrm{Cu}$ pillar packages, in Paper Presented at the 68th Electronic Components and Technology Conference, San Diego, CA, USA (2018)

[27] J. Han, H. Cen, M. Li, Acta Metall. Sin. (Engl. Lett.) 25, 214 (2012) 